\title{
Severity of Sjögren's Syndrome Keratoconjunctivitis Sicca Increases with Increased Percentage of Conjunctival Antigen-Presenting Cells
}

\author{
Stephen C. Pflugfelder ${ }^{1, *}$, Fang Bian ${ }^{1}$, Koray Gumus ${ }^{1,2}$, William Farley ${ }^{1}$, Michael E. Stern ${ }^{1}$ and \\ Cintia S. De Paiva ${ }^{1}$ (D) \\ 1 Department of Ophthalmology, Baylor College of Medicine, Houston, TX 77030, USA; \\ Fang.Bian@bcm.edu (F.B.); dkorayg@hotmail.com (K.G.); Bill.Farley@bcm.edu (W.F.); \\ michaelestern4@gmail.com (M.E.S.); cintiadp@bcm.edu (C.S.D.P.) \\ 2 Department of Ophthalmology, Erciyes University School of Medicine, 38039 Kayseri, Turkey \\ * Correspondence: stevenp@bcm.edu; Tel.: +1-713-798-6100; Fax: +1-713-798-1457
}

Received: 18 August 2018; Accepted: 12 September 2018; Published: 14 September 2018

\begin{abstract}
This study investigated the relationship between clinical severity and percentage of conjunctival antigen-presenting cells (APCs) in Sjögren's syndrome (SS)-associated keratoconjunctivitis sicca (KCS). KCS clinical severity was based on symptom severity, tear volume, tear break-up time, and ocular surface dye staining. Conjunctival goblet cell density (GCD) was measured in periodic acid Schiff (PAS)-stained membranes. Conjunctival cells obtained by impression cytology were used for flow cytometry to measure percentages of $\mathrm{CD}^{2} 5^{+} \mathrm{HLA}-\mathrm{DR}{ }^{+} \mathrm{APC}$ and mature $\mathrm{CD} 11 \mathrm{c}^{+} \mathrm{CD} 86^{+}$dendritic cells (DCs). Compared to normal conjunctiva, the percentages of HLA-DR ${ }^{+}$ and $\mathrm{CD} 11 \mathrm{c}^{+} \mathrm{CD} 86^{+}$cells were higher in the conjunctiva of the KCS group $(p<0.05)$. The percentage of $\mathrm{CD} 45^{+} \mathrm{HLA}-\mathrm{DR}^{+}$cells positively correlated with clinical severity $(r=0.71, p<0.05)$ and negatively correlated with GCD $(r=-0.61, p<0.05)$. Clinical severity also negatively correlated with GCD $(r=-0.54, p<0.05)$. These findings indicate that a higher percentage of APCs and mature DCs in the conjunctiva is associated with more severe KCS in SS. These APCs may contribute to the generation of the pathogenic Th1 cells that cause goblet cell loss in KCS.
\end{abstract}

Keywords: Sjögren's syndrome; dry eye; goblet cells; antigen-presenting cells; dendritic cells

\section{Introduction}

Sjögren's syndrome (SS) causes severe aqueous-deficient dry eye and ocular surface disease, termed keratoconjunctivitis sicca (KCS) [1,2]. Dysfunction and loss of mucin-producing conjunctival goblet cells is a key pathological feature of SS KCS [1,3]. Increased expression of the Thelper 1 (Th1) cytokine Interferon gamma (IFN- $\gamma$ ), which induces an unfolded protein response and apoptosis in (goblet cells, has been found in KCS [3-5]. In addition to producing mucins that lubricate and protect the ocular surface, goblet cells have also been found to produce immunomodulatory factors, including retinoic acid, transforming growth factor beta 2 (TGF- $\beta 2$ ), and mucin 2 (MUC2), which are important for maintaining immune tolerance [6-10]. Conjunctival goblet cells serve as passages for ocular surface antigens to antigen-presenting cells (APCs) located in the basement membrane zone and stroma [6]. Goblet cell mucin has been found to mix with ovalbumin (OVA) antigen as it passes through GAPs, and immune tolerance to topically applied OVA is lost in the sterile alpha motif (SAM)-pointed domain containing (E-twenty-six) ETS transcription factor (Spdef) knockout (KO) mouse strain that lacks goblet cells $[6,8]$. Goblet-cell-produced retinoic acid has been found to suppress differentiation and stimulate production of the Th1-inducing cytokine interleukin 12 (IL-12) by bone-marrow-derived 
APCs [9]. The Spdef strain has been found to have a higher number of IL-12-producing APCs in the conjunctiva compared to the wild-type strain [8].

The percentage of HLA-DR ${ }^{+}$cells in the conjunctiva has been reported to increase in dry eye and has been used as a severity marker [11]. HLA-DR is primarily expressed by APCs, including monocytes, macrophages and dendritic cells, but it can be induced in epithelial cells that are exposed to inflammatory cytokines, such as IFN- $\gamma$ [12]. Previously reported studies have compared the percentages of HLA-DR ${ }^{+}$cells between normal and dry eyes in the entire conjunctival cell population or in epithelial cells alone [13-17]. Changes in the percentages of APCs and the relationship between antigen-presenting and goblet cell densities in SS KCS has not been investigated. The purpose of this study was to investigate the relationship between clinical severity and density of conjunctival APCs and goblet cells in SS-associated KCS.

\section{Results}

\subsection{Clinical Severity}

Eight control subjects and 11 SS KCS patients were enrolled. Goblet cells could not be evaluated in samples from one control and two SS patients because of poor sample quality, and they were excluded from all statistical analyses. The control subjects had no eye irritation symptoms and no clinical signs of KCS. The KCS patients had a mean Dry Eye Workshop (DEWS) clinical severity score of $2.5 \pm 0.72$ (range 1-3; Figure 1). The goblet cell density (GCD) was $42 \%$ lower in the KCS group (39.6 \pm 40.5 ) than the control group $(68.2 \pm 40.4, p=0.008$ vs. KCS; Figure 1$)$.

A

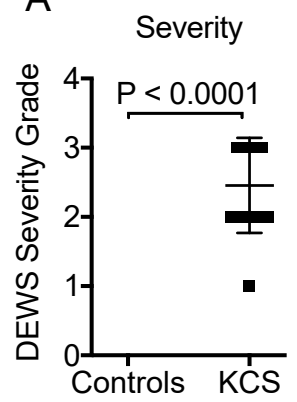

B

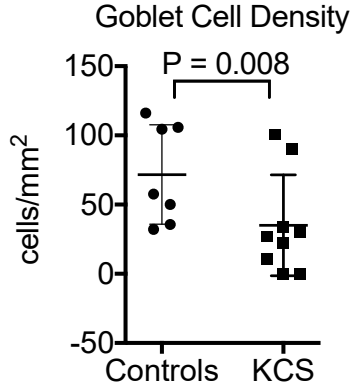

Figure 1. Clinical severity (A) and conjunctival goblet cell density $(\mathbf{B})$ in controls $(n=7)$ and Sjögren's syndrome keratoconjunctivitis sicca (KCS) subjects $(n=9)$. Mean + standard deviation (SD). Mann-Whitney test.

\subsection{Conjunctival Antigen-Presenting Cells}

The percentage of bone-marrow-derived $\mathrm{CD} 45^{+}$cells in the conjunctiva obtained by impression cytology from all three sites-superior bulbar (SB), nasal bulbar (NB), and temporal bulbar (TB)—was significantly higher in the KCS group $(p<0.02)$ and approached significance in cells obtained from the SB alone $(p<0.06)$.

The percentage of HLA-DR ${ }^{+}$cells obtained by conjunctival impression cytology from dry eye subjects has been found to be significantly higher than the control in a number of previously reported studies $[13-15,17]$. HLA-DR is expressed by APCs but can also be expressed by epithelial cells that are exposed to inflammatory/immune cytokines, such as IFN- $\gamma$ [12]. We examined differences in bone-marrow-derived HLA-DR ${ }^{+}$cells between control and SS KCS because these cells can present antigen and initiate adaptive immunity. HLA-DR ${ }^{+}$antigen-presenting cells have been noted in and below the conjunctival epithelium in humans and mice (Figure 2A) $[6,18]$. As confirmation of our gating strategy on $\mathrm{CD}^{+} 5^{+}$cells, we found that $>99 \%$ of the HLA-DR mean fluorescence intensity (MFI) was in $\mathrm{CD}^{+} 5^{+}$cells obtained from the conjunctiva of the control and KCS eyes (Figure 2). The percentages of HLA-DR ${ }^{+} \mathrm{CD} 45^{+}$antigen-presenting cells and $\mathrm{HLA}-\mathrm{DR}^{+} \mathrm{CD} 45^{+} \mathrm{CD} 11 \mathrm{c}^{+}$dendritic 
cells were higher in the $\mathrm{SB}$ and the combined $(\mathrm{SB}+\mathrm{NB}+\mathrm{TB})$ groups in KCS than the control eyes (Figure 3A-E); however, percentages in the exposed NB + TB conjunctiva were not greater than the control. A similar phenomenon was observed for $\mathrm{CD} 45^{+} \mathrm{CD} 11 \mathrm{c}^{+} \mathrm{CD} 86^{+}$mature dendritic cells (DCs), which were greater in the SB and the combined (SB + NB + TB) groups (Figure 4A-C). The analyses were repeated by comparing the absolute cell number for each population (Supplemental Table S1) and the significance between group differences were the same as those seen in the percentage comparisons.
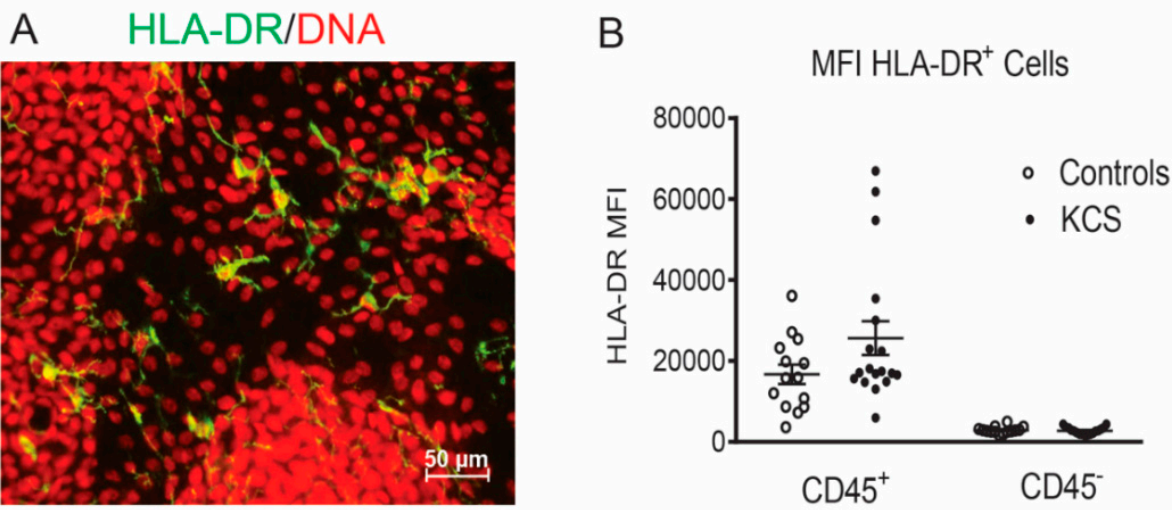

Figure 2. HLA-DR intensity in gated $C D 45^{+}$cells. (A) Merged image of laser confocal micrograph of dendritic cells (DC) in human conjunctival impression cytology from a normal subject stained with HLA-DR (green) and nuclei stained with red propidium iodide. (B) Mean fluorescent intensity (MFI) of HLA-DR ${ }^{+}$cells in CD45-gated cell population obtained by conjunctival impression cytology from controls $(n=7)$ and KCS subjects $(n=9)$. Data shown as scatter plots with mean $\pm \mathrm{SD}$.

A

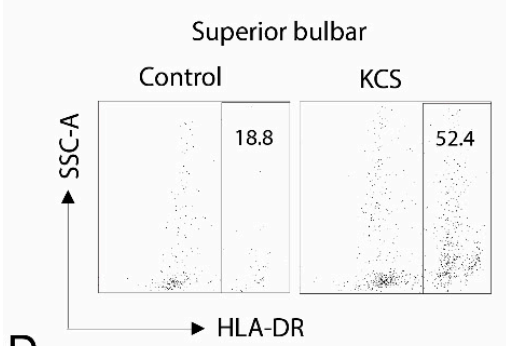

$\mathrm{D}$

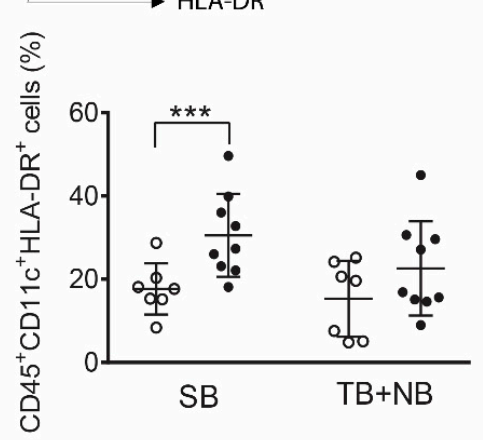

$\mathrm{B}$

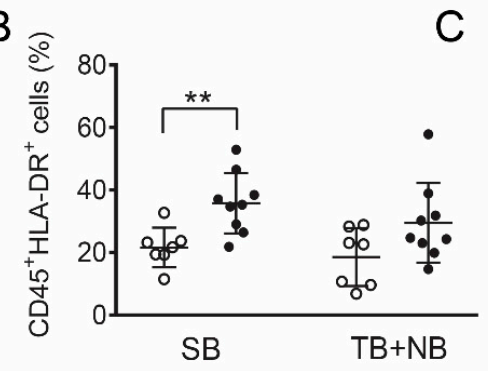

E

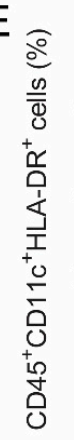

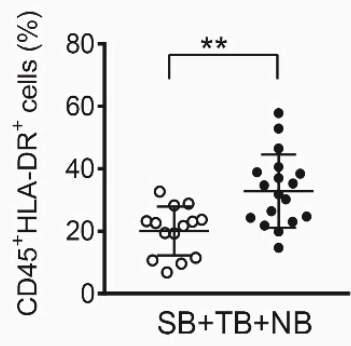

$\mathrm{SB}+\mathrm{TB}+\mathrm{NB}$

Figure 3. Increased percentage of $\mathrm{HLA}^{-\mathrm{DR}^{+}}$cells in KCS patients. (A) Representative dot plots of flow cytometry showing HLA-DR ${ }^{+}$cells gated from live $\mathrm{CD} 45^{+}$population in the control and KCS samples. (B) Accumulative data showing percentage of CD45 ${ }^{+} \mathrm{HLA}-\mathrm{DR}^{+}$cells in the superior bulbar (SB) and nasal bulbar (NB) + temporal bulbar (TB) conjunctiva in the control $(n=7)$ and Sjögren's syndrome (SS) subjects $(n=9)$ and $(C)$ the corresponding accumulative data for all three bulbar conjunctival sites. (D) Accumulative data showing percentage of $\mathrm{CD} 45^{+} \mathrm{CD} 11 \mathrm{c}^{+} \mathrm{HLA}-\mathrm{DR}{ }^{+}$cells in SB and NB $+\mathrm{TB}$ conjunctiva in the control $(n=7)$ and SS subjects $(n=9)$ and $(\mathbf{E})$ the corresponding accumulative data for all three bulbar conjunctival sites. Data shown as scatter plots with mean \pm SD. ${ }^{* *} p<0.01$; *** $p<0.001$, Mann-Whitney test. 
A

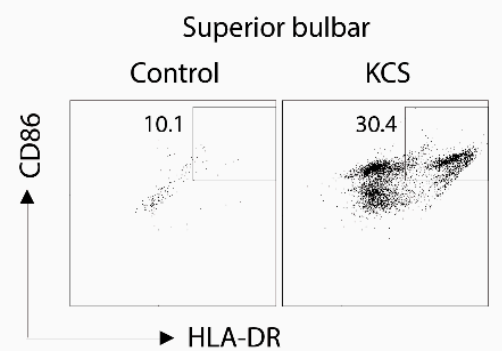

$\mathrm{B} \curvearrowright$

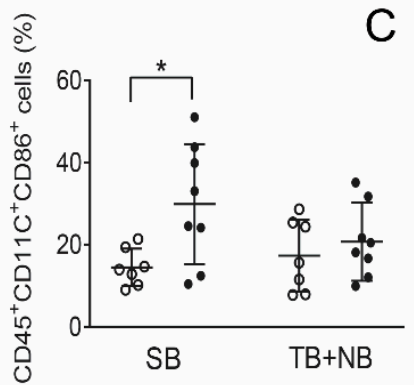

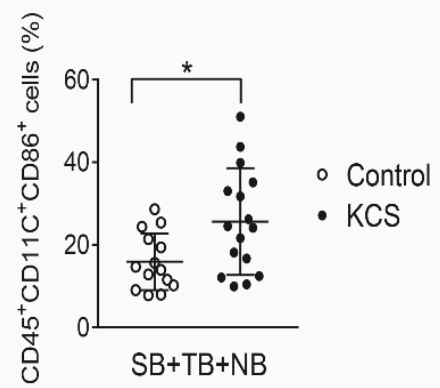

Figure 4. (A) Representative scatter plots of $\mathrm{HLA}-\mathrm{DR}^{+} \mathrm{CD} 86^{+}$in representative control and KCS patient. (B) Graphs comparing percentage of $\mathrm{CD} 11 \mathrm{c}^{+} \mathrm{CD} 86^{+}$cells in the $\mathrm{SB}$ and $\mathrm{NB}+\mathrm{TB}$ conjunctiva in the control $(n=7)$ and SS subjects $(n=8)$ and $(\mathbf{C})$ corresponding graphs for all three bulbar conjunctival sites. Data shown as scatter plots with mean \pm SD. ${ }^{*} p<0.05$ Mann-Whitney test.

\subsection{Correlations between Conjunctival APCs and KCS Severity Markers}

The Dry Eye Workshop has reported a categorical clinical severity score for KCS based on severity of symptoms, tear break-up time, density of staining of the corneal epithelium with fluorescein and the conjunctival epithelium with lissamine green dye, and other clinical signs [19]. In our study, clinical severity based on this score negatively correlated with GCD $(r=-0.5, p<0.05)$ and positively correlated with the percentage of $\mathrm{CD}^{2} 5^{+} \mathrm{HLA}^{-\mathrm{DR}^{+}}$cells $(r=0.77, p<0.01)$ (Figure 5, top). GCD negatively correlated with percentage of HLA-DR ${ }^{+}$cells $(r=-0.54, p<0.05)$ but not with the percentage of $\mathrm{CD} 86^{+}$cells (Figure 5, bottom). None of the correlations were significant if the control subjects were excluded from the analyses.
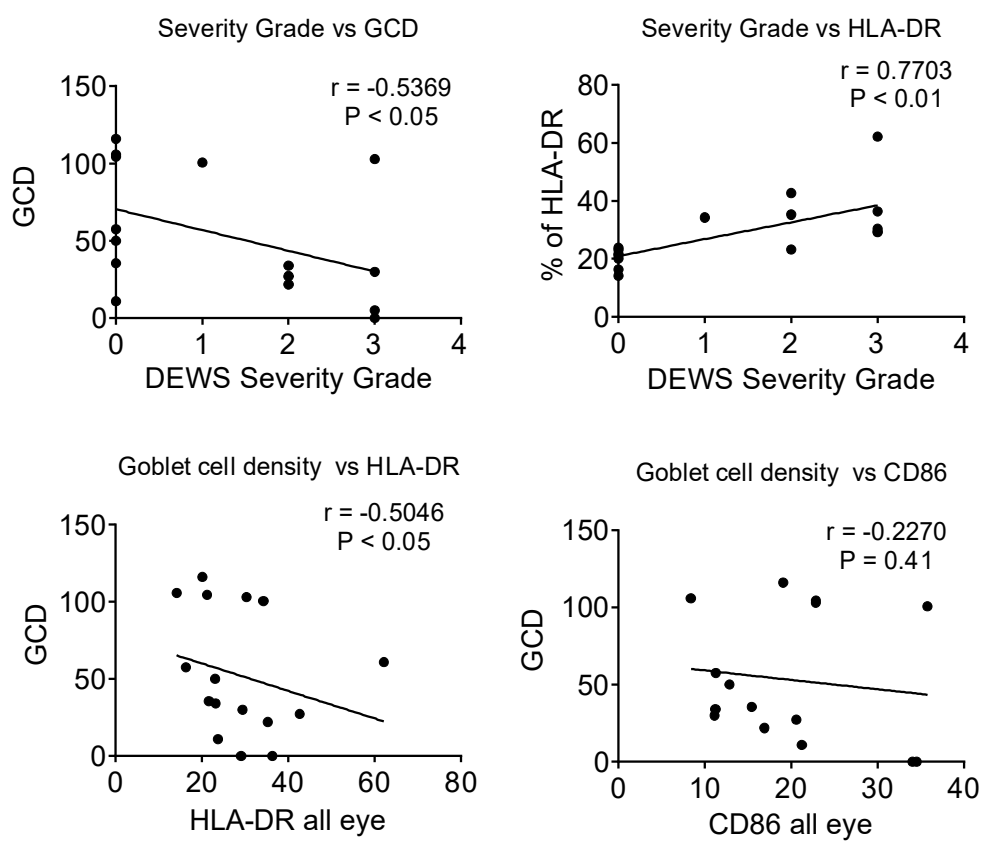

Figure 5. Correlations between clinical severity and goblet cell density (GCD) (upper left), clinical severity and percentage of $\mathrm{HLA}-\mathrm{DR}^{+}$cells (upper right), percentage of $\mathrm{HLA}-\mathrm{DR}^{+}$cells and GCD (lower left), and percentage of $\mathrm{CD}^{+} 6^{+}$cells and GCD (lower right). Correlations included the control and SS KCS subjects. Spearman $r$ and $p$ values are provided on graphs.

\section{Discussion}

This study found an increased percentage of bone-marrow-derived cells and APCs in the conjunctiva of patients with SS-associated KCS. A previously reported study had found no difference in 
percentage of $\mathrm{CD} 45^{+}$cells in the conjunctiva between aqueous tear-deficient patients and normal eyes, but the percentage of patients with SS in this cohort was not specified [20]. Our finding of increased $\mathrm{CD} 45^{+}$cells in the conjunctiva of SS suggests that there is greater infiltration of bone-marrow-derived cells in this systemic autoimmune condition that has KCS as a defining feature [21]. We also found the percentage of bone-marrow-derived HLA-DR ${ }^{+}$cells was higher in the SS conjunctiva. These cells could potentially serve as APCs that participate in the adaptive immune response that develops in dry eye $[22,23]$. There is also a possibility that the increased IFN- $\gamma$ expression in the SS conjunctiva stimulates more HLA-DR positivity in resident APCs [3].

We evaluated the percentages of HLA-DR ${ }^{+}$APCs in the nonexposed (superior) and exposed nasal and temporal regions of the bulbar conjunctiva and found a significant difference in percentage between the control and KCS in the superior bulbar conjunctiva. The cause for the greater difference in density of APCs in the superior conjunctiva of SS KCS remains to be determined; it may be because this region is subjected to frequent mechanical trauma from blinking, which promotes leukocyte chemotaxis. This is consistent with the finding of Reinoso and colleagues that the number of $\mathrm{T}$ cells and dead epithelial cells are higher in the superior than the inferior conjunctiva in normal eyes [24]. Our finding of increased APC density in the superior conjunctiva may have implications for pathogenesis of KCS and should be confirmed in a separate study. We also found the percentage of APCs expressing the maturation marker CD86 was increased in the SS conjunctiva. CD86 is a costimulatory marker expressed by APCs, which is required for robust antigen-specific activation of T helper cells [25].

We found the number of conjunctival APCs correlated with categorical clinical severity and inversely correlated with the number of goblet cells. It should be noted that while the correlations between goblet cells and disease severity and percentage of HLA-DR ${ }^{+}$APCs were significant, the correlation coefficients were relatively weak ( $r$ approximately 0.5$)$ and significance was lost when controls were omitted. This suggests that there are factors other than reduced GCD that contribute to disease severity and HLA-DR expression by APCs. Our findings are consistent with those in the mouse desiccating stress dry eye model that has features resembling SS KCS, including significant goblet cell loss $[5,26,27]$. Conjunctival APCs are necessary to initiate the adaptive immune response as depletion of phagocytic APCs with clodronate liposomes prevent the T cell-mediated immune response to desiccating environmental stress in this model [28]. It remains to be determined whether reduced conjunctival goblet cell density in SS KCS results in increased APC infiltration/maturation or whether APCs increase in the conjunctiva due to the systemic autoimmune disease and promote the Th1 immune response with increased IFN- $\gamma$ expression that has been observed in human KCS. The Spdef mouse strain that lacks goblet cells has been found to have an increased number of APCs with greater production of IL-12 in their conjunctiva [8]. The findings of this study suggest that APCs are potential therapeutic targets, and therapies suppressing APC infiltration and activation may have efficacy in SS-associated KCS. A weakness of the study is the small sample size and the lack of a non-SS aqueous-deficient control group with less severe disease. The significance of our findings will have greater strength if they are confirmed in another study with a larger sample size that also includes a non-SS aqueous deficiency (ATD) group.

\section{Methods}

\subsection{Human Subjects}

The study was conducted in accordance with the Declaration of Helsinki, and the Baylor College of Medicine Institutional Review Board approved the protocol and informed consent form prior to study initiation (H-8950, 30 March 2016). Written informed consent was obtained from all participants after explanation of the purpose and possible consequences of the study. Patients with SS were recruited from the multispecialty SS clinic at Baylor College of Medicine (BCM). All SS patients had a complete ocular, oral, and rheumatologic evaluation, including a panel of serum autoantibodies, and met proposed American College of Rheumatology diagnostic criteria for SS [29]. 
Symptom assessment in dry eye (SANDE) and Ocular Surface Disease Index (OSDI) symptom questionnaires, fluorescein tear break-up time (TBUT), Schirmer I test, cornea fluorescein and conjunctival lissamine green dye staining, and tear meniscus height measurement using optical coherence tomography (OCT) were performed as previously described [30,31]. The ocular surface clinical parameters were all measured by the same observer (S.C.P.). Dry Eye Workshop (DEWS) criteria were used to grade clinical severity [19].

Control subjects had no eye irritation, a TBUT $\geq 8 \mathrm{~s}$, Schirmer $1 \geq 10 \mathrm{~mm}$, tear meniscus height $\geq 240 \mu \mathrm{m}$, and no meibomian gland disease. Subjects were excluded if they had prior laser assisted in situ keratomilieusis (LASIK) or corneal transplantation surgery, cataract surgery in the past year, punctal occlusion with plugs or cautery, a history of contact lens wear, use of topical medications other than preservative-free artificial tears, or chronic use of systemic medications known to reduce tear production. They were instructed not to instill any tear drops on the day of the evaluation.

\subsection{Conjunctival Goblet Cell Density}

Goblet cell density was measured in impression cytology specimens taken from the temporal bulbar conjunctiva of the left eye. Membranes were fixed and stained by periodic acid Schiff (PAS) reagent as previously described [3,32]. Goblet cells were counted in five representative images taken using image analysis software (Nikon Elements, Garden City, NY, USA), normalized per area, and expressed as GC/ $/ \mathrm{mm}^{2}$. GCD was measured in digital images of PAS-stained membranes taken from the temporal bulbar conjunctiva of the left eye.

\subsection{Flow Cytometry}

APCs were obtained from impression cytology of the superior and exposed (nasal + temporal) bulbar conjunctiva of the right eye. Flow cytometry was used to measure the percentage of bone-marrow-derived (CD45) cells that were positive for HLA-DR, CD11c, and CD86 in the conjunctival cells. After the cytology membranes were removed from the eye, they were placed in capped tube containing Roswell Park Memorial Institute (RPMI) media and placed on an oscillating shaker for $1 \mathrm{~h}$. Any remaining cells on the membrane were removed with a cytology brush and were pelleted by centrifugation. Cells were stained with a panel of antibodies including CD45-APC (clone 2D1, eBioscience, Waltham, MA, USA), HLA-DR-FITC (clone L243; Thermofisher, Waltham, MA, USA), CD11c-PE (clone B-ly6, BD Pharmingen, San Diego, CA, USA) and CD86-Pacific blue (clone IT2.2, Biolegend, San Diego, CA, USA), and blue dead Fixable Dead Cell Stain ${ }^{\mathrm{TM}}$ (Life Technologies, Grand Island, NY, USA). Negative controls were isotype control antibodies for each color. Flow cytometry was performed with a BD Canto II Benchtop cytometer with BD Diva software version 6.7 (BD Biosciences, San Jose, CA, USA). Cells were initially gated by CD45 vs. live/dead dye followed by two single gates, then gated by HLA-DR followed by CD11c and CD86. A minimum of 100,000 events were acquired. Final data was analyzed with FlowJo software version 10 (Tree Star Inc., Ashland, OR, USA).

\subsection{Statistical Analysis}

The sample size was calculated using StatMate 2 (GraphPad Software Inc., San Diego, CA, USA) based on pilot studies to have at least $90 \%$ power to detect differences with an alpha of 0.05 . Based on normality, parametric Student's $t$-test or nonparametric Mann-Whitney $U$ tests were performed for statistical comparisons with an alpha of 0.05 using GraphPad Prism 7.0 software (GraphPad Software Inc.). Spearman correlations between severity and percentages of immune cell markers were calculated. A sample size of eight subjects per group had $90 \%$ power of detecting a between-group mean difference of $13 \%$ for HLA-DR $(\alpha=0.05)$.

Supplementary Materials: Supplementary materials can be found at http:/ /www.mdpi.com/1422-0067/19/9/2760/s1. 
Author Contributions: S.C.P., C.S.D.P., and M.E.S. designed the experiments. C.S.D.P., F.B., W.F. and K.G. performed the experiments. All authors analyzed the data and contributed to the manuscript, which was reviewed and approved by all authors.

Funding: This work was supported by NIH/NEI EY011915 (S.C.P.), NIH Core Grants-EY002520 \& EY020799, NIH Training Grant T32-AI053831 (F.B.), RPB Research to Prevent Blindness, The Oshman Foundation, William Stamps Farish Fund, The Hamill Foundation, The Sid W. Richardson Foundation, the Scientific and Technological Research Council of Turkey (K.G.), Biology of Inflammation Center Baylor College of Medicine and by the Cytometry and Cell Sorting Core at Baylor College of Medicine, which is funded by the NIH NIAID P30AI036211, NCI P30CA125123, and NCRR S10RR024574.

Conflicts of Interest: The authors declare no conflict of interest.

\section{References}

1. Pflugfelder, S.C.; Huang, A.J.; Feuer, W.; Chuchovski, P.T.; Pereira, I.C.; Tseng, S.C. Conjunctival cytologic features of primary Sjogren's syndrome. Ophthalmology 1990, 97, 985-991. [CrossRef]

2. Pflugfelder, S.C.; Tseng, S.C.; Yoshino, K.; Monroy, D.; Felix, C.; Reis, B.L. Correlation of goblet cell density and mucosal epithelial membrane mucin expression with rose bengal staining in patients with ocular irritation. Ophthalmology 1997, 104, 223-235. [CrossRef]

3. Pflugfelder, S.C.; De Paiva, C.S.; Moore, Q.L.; Volpe, E.A.; Li, D.Q.; Gumus, K.; Zaheer, M.L.; Corrales, R.M. Aqueous tear deficiency increases conjunctival interferon- $\gamma$ (IFN- $\gamma$ ) expression and goblet cell loss. Investig. Ophthalmol. Vis. Sci. 2015, 56, 7545-7550. [CrossRef] [PubMed]

4. Coursey, T.G.; Tukler Henriksson, J.; Barbosa, F.L.; de Paiva, C.S.; Pflugfelder, S.C. Interferon- $\gamma$-induced unfolded protein response in conjunctival goblet cells as a cause of mucin deficiency in Sjogren syndrome. Am. J. Pathol. 2016, 186, 1547-1558. [CrossRef] [PubMed]

5. De Paiva, C.S.; Villarreal, A.L.; Corrales, R.M.; Rahman, H.T.; Chang, V.Y.; Farley, W.J.; Stern, M.E.; Niederkorn, J.Y.; Li, D.Q.; Pflugfelder, S.C. Dry eye-induced conjunctival epithelial squamous metaplasia is modulated by interferon- $\gamma$. Investig. Ophthalmol. Vis. Sci. 2007, 48, 2553-2560. [CrossRef] [PubMed]

6. Barbosa, F.L.; Xiao, Y.; Bian, F.; Coursey, T.G.; Ko, B.Y.; Clevers, H.; de Paiva, C.S.; Pflugfelder, S.C. Goblet cells contribute to ocular surface immune tolerance-implications for dry eye disease. Int. J. Mol. Sci. 2017, $18,978$. [CrossRef] [PubMed]

7. Contreras-Ruiz, L.; Masli, S. Immunomodulatory cross-talk between conjunctival goblet cells and dendritic cells. PLoS ONE 2015, 10, e0120284. [CrossRef] [PubMed]

8. Ko, B.Y.; Xiao, Y.; Barbosa, F.L.; de Paiva, C.S.; Pflugfelder, S.C. Goblet cell loss abrogates ocular surface immune tolerance. JCI Insight 2018, 3. [CrossRef] [PubMed]

9. Xiao, Y.; De Paiva, C.S.; Yu, Z.; Guimaraes de Souza, R.; Li, D.Q.; Pflugfelder, S.C. Goblet cell produced retinoic acid suppresses CD86 expression and IL-12 production in bone marrow derived cells. Int. Immunol. 2018. [CrossRef] [PubMed]

10. Shan, M.; Gentile, M.; Yeiser, J.R.; Walland, A.C.; Bornstein, V.U.; Chen, K.; He, B.; Cassis, L.; Bigas, A.; Cols, M.; et al. Mucus enhances gut homeostasis and oral tolerance by delivering immunoregulatory signals. Science 2013, 342, 447-453. [CrossRef] [PubMed]

11. Epstein, S.P.; Gadaria-Rathod, N.; Wei, Y.; Maguire, M.G.; Asbell, P.A. HLA-DR expression as a biomarker of inflammation for multicenter clinical trials of ocular surface disease. Exp. Eye Res. 2013, 111, 95-104. [CrossRef] [PubMed]

12. De Saint Jean, M.; Brignole, F.; Feldmann, G.; Goguel, A.; Baudouin, C. Interferon- $\gamma$ induces apoptosis and expression of inflammation-related proteins in Chang conjunctival cells. Investig. Ophthalmol. Vis. Sci. 1999, 40, 2199-2212.

13. Rolando, M.; Barabino, S.; Mingari, C.; Moretti, S.; Giuffrida, S.; Calabria, G. Distribution of conjunctival HLA-DR expression and the pathogenesis of damage in early dry eyes. Cornea 2005, 24, 951-954. [CrossRef] [PubMed]

14. Pisella, P.J.; Brignole, F.; Debbasch, C.; Lozato, P.A.; Creuzot-Garcher, C.; Bara, J.; Saiag, P.; Warnet, J.M.; Baudouin, C. Flow cytometric analysis of conjunctival epithelium in ocular rosacea and keratoconjunctivitis sicca. Ophthalmology 2000, 107, 1841-1849. [CrossRef] 
15. Brignole, F.; Pisella, P.J.; Goldschild, M.; De Saint Jean, M.; Goguel, A.; Baudouin, C. Flow cytometric analysis of inflammatory markers in conjunctival epithelial cells of patients with dry eyes. Investig. Ophthalmol. Vis. Sci. 2000, 41, 1356-1363.

16. Versura, P.; Profazio, V.; Schiavi, C.; Campos, E.C. Hyperosmolar stress upregulates HLA-DR expression in human conjunctival epithelium in dry eye patients and in vitro models. Investig. Ophthalmol. Vis. Sci. 2011, 52, 5488-5496. [CrossRef] [PubMed]

17. Mrugacz, M.; Zak, J.; Bakunowicz-Lazarczyk, A.; Wysocka, J.; Minarowska, A. Flow cytometric analysis of HLA-DR antigen in conjunctival epithelial cells of patients with cystic fibrosis. Eye 2007, 21, 1062-1066. [CrossRef] [PubMed]

18. Sheppard, J.D., Jr.; Singh, R.; McClellan, A.J.; Weikert, M.P.; Scoper, S.V.; Joly, T.J.; Whitley, W.O.; Kakkar, E.; Pflugfelder, S.C. Long-term supplementation with n-6 and n-3 PUFAs improves moderate-to-severe keratoconjunctivitis sicca: A randomized double-blind clinical trial. Cornea 2013, 32, 1297-1304. [CrossRef] [PubMed]

19. Pflugfelder, S.T.; Geerling, G.; Kinoshita, S.; Wilson, C. Management and therapy of dry eye disease: Report of the management and therapy subcommittee of the international dry eye workshop (2007). Ocul. Surf. 2007, $5,163-178$.

20. Barabino, S.; Montaldo, E.; Solignani, F.; Valente, C.; Mingari, M.C.; Rolando, M. Immune response in the conjunctival epithelium of patients with dry eye. Exp. Eye Res. 2010, 91, 524-529. [CrossRef] [PubMed]

21. Whitcher, J.P.; Shiboski, C.H.; Shiboski, S.C.; Heidenreich, A.M.; Kitagawa, K.; Zhang, S.; Hamann, S.; Larkin, G.; McNamara, N.A.; Greenspan, J.S.; Daniels, T.E. A simplified quantitative method for assessing keratoconjunctivitis sicca from the Sjogren's Syndrome International Registry. Am. J. Ophthalmol. 2010, 149, 405-415. [CrossRef] [PubMed]

22. Stern, M.E.; Schaumburg, C.S.; Pflugfelder, S.C. Dry eye as a mucosal autoimmune disease. Int. Rev. Immunol. 2013, 32, 19-41. [CrossRef] [PubMed]

23. Pflugfelder, S.C.; de Paiva, C.S. The pathophysiology of dry eye disease: What we know and future directions for research. Ophthalmology 2017, 124, S4-S13. [CrossRef] [PubMed]

24. Reinoso, R.; Martin-Sanz, R.; Martino, M.; Mateo, M.E.; Blanco-Salado, R.; Calonge, M.; Corell, A. Topographical distribution and characterization of epithelial cells and intraepithelial lymphocytes in the human ocular mucosa. Mucosal Immunol. 2012, 5, 455-467. [CrossRef] [PubMed]

25. Said, A.; Weindl, G. Regulation of Dendritic Cell Function in Inflammation. J. Immunol. Res. $2015,2015$. [CrossRef] [PubMed]

26. De Paiva, C.S.; Chotikavanich, S.; Pangelinan, S.B.; Pitcher, J.D., 3rd; Fang, B.; Zheng, X.; Ma, P.; Farley, W.J.; Siemasko, K.F.; Niederkorn, J.Y.; et al. IL-17 disrupts corneal barrier following desiccating stress. Mucosal Immunol. 2009, 2, 243-253. [CrossRef] [PubMed]

27. Yoon, K.C.; De Paiva, C.S.; Qi, H.; Chen, Z.; Farley, W.J.; Li, D.Q.; Pflugfelder, S.C. Expression of Th-1 chemokines and chemokine receptors on the ocular surface of C57BL/ 6 mice: Effects of desiccating stress. Investig. Ophthalmol. Vis. Sci. 2007, 48, 2561-2569. [CrossRef] [PubMed]

28. Schaumburg, C.S.; Siemasko, K.F.; De Paiva, C.S.; Wheeler, L.A.; Niederkorn, J.Y.; Pflugfelder, S.C.; Stern, M.E. Ocular surface APCs are necessary for autoreactive T cell-mediated experimental autoimmune lacrimal keratoconjunctivitis. J. Immunol. 2011, 187, 3653-3662. [CrossRef] [PubMed]

29. Shiboski, S.C.; Shiboski, C.H.; Criswell, L.; Baer, A.; Challacombe, S.; Lanfranchi, H.; Schiodt, M.; Umehara, H.; Vivino, F.; Zhao, Y.; et al. Sjogren's International Collaborative Clinical Alliance Research, G. American College of Rheumatology classification criteria for Sjogren's syndrome: A data-driven, expert consensus approach in the Sjogren's International Collaborative Clinical Alliance cohort. Arthrit. Care Res. 2012, 64, 475-487.

30. Rao, K.; Farley, W.J.; Pflugfelder, S.C. Association between high tear epidermal growth factor levels and corneal subepithelial fibrosis in dry eye conditions. Investig. Ophthalmol. Vis. Sci. 2010, 51, 844-849. [CrossRef] [PubMed] 
31. Tung, C.I.; Perin, A.F.; Gumus, K.; Pflugfelder, S.C. Tear meniscus dimensions in tear dysfunction and their correlation with clinical parameters. Am. J. Ophthalmol. 2014, 157, 301-310. [CrossRef] [PubMed]

32. Pflugfelder, S.C.; De Paiva, C.S.; Villarreal, A.L.; Stern, M.E. Effects of sequential artificial tear and cyclosporine emulsion therapy on conjunctival goblet cell density and transforming growth factor- $\beta 2$ production. Cornea 2008, 27, 64-69. [CrossRef] [PubMed] 